\title{
Pelatihan Pembuatan Hidroponik DFT Model Meja Kepada Siswa SMAN 1 Batur Banjarnegara
}

\author{
Sapto Wibowo*1 \\ 1Program Studi Agroindustri, Politeknik Banjarnegara \\ *e-mail: sapto wbw@yahoo.com ${ }^{1}$
}

\begin{abstract}
DFT hydroponics is a hydroponic method in which plant roots are immersed in a nutrient solution with a height of 3-4 cm, which is circulated continuously for 24 hours. So far, State High School (SHS) 1 of Batur students do not know about hydroponics, especially in the construction of hydroponic models. Thus, students do not yet have skills in one of the double track programs of SHS 1 of Batur, namely the field of hydroponic plant cultivation. Therefore, it is necessary to conduct training on the manufacture of table model DFT hydroponics, which is a simple hydroponic model in construction and easy to make, with the aim of providing knowledge, skills, and laying the foundation for an entrepreneurial spirit in students. The method used is counseling on hydroponic theory and training on the practice of making table model DFT hydroponics. The result is that at the end of the activity, the students' knowledge level increased 88\%-100\% with an average of $94 \%$, while the students' skill level increased $82 \%-100 \%$ with an average of $92.5 \%$. This shows that the students of SHS 1 of Batur are able to absorb the counseling and training materials provided..
\end{abstract}

Keywords: DFT, Hydroponics, Table, SHS, Students

\begin{abstract}
Abstrak
Hidroponik DFT adalah suatu metode hidroponik di mana akar tanaman berada dalam larutan nutrisi dengan ketinggian 3-4 cm, yang tersirkulasi secara kontinu selama 24 jam. Selama ini siswa SMAN 1 Batur belum mengetahui tentang hidroponik, terutama dalam pembuatan konstruksi model hidroponik. Dengan demikian, para siswa belum memiliki keterampilan pada salah satu program double track SMAN 1 Batur, yaitu bidang budidaya tanaman hidroponik. Oleh karena itu perlu dilakukan pelatihan pembuatan hidroponik DFT model meja, yang merupakan model hidroponik sederhana konstruksinya dan mudah dibuat, dengan tujuan memberikan pengetahuan, keterampilan, dan meletakkan dasar jiwa kewirausahaan pada siswa. Metode yang digunakan adalah penyuluhan tentang teori hidroponik dan pelatihan tentang praktik pembuatan hidroponik DFT model meja. Hasilnya yaitu pada akhir kegiatan tingkat pengetahuan siswa meningkat 88\%-100\% dengan rata-rata 94\%, sedang tingkat keterampilan siswa meningkat 82\%100\% dengan rata-rata 92,5\%. Hal ini menunjukkan bahwa para siswa SMAN 1 Batur mampu menyerap materi penyuluhan dan pelatihan yang diberikan.
\end{abstract}

Kata kunci: DFT, Hidroponik, Meja, Siswa, SMAN

\section{PENDAHULUAN}

"Hidroponik adalah budidaya tanaman tanpa menggunakan media tanah (soilless) yang dilakukan secara terkendali, baik dalam rumah kaca (greenhouse) serta dengan menggunakan larutan nutrisi sebagai unsur hara tanaman. Hidroponik semakin diminati oleh petani maupun praktisi karena produk yang dihasilkan lebih terjamin baik dari segi kualitas maupun kuantitas, dan hal ini sesuai dengan permintaan konsumen akan produk sayuran yang aman untuk dikonsumsi" (Ginting, 2019). Sedang Saputra et al. (sebagaimana dikutip dalam Gayatri \& Mahyuni, 2021) menyatakan bahwa "media tanam yang digunakan dalam hidroponik tidak menggunakan tanah, tetapi dengan memanfaatkan air".

Hidayah et al. (2020) menyatakan bahwa "hidroponik Deep Flow Technique (DFT) memilki prinsip kerja yaitu menyirkulasikan larutan nutrisi pada aliran tertutup secara kontinu selama 24 jam". Selanjutnya Wibowo (2020) menyatakan bahwa "salah satu model hidroponik DFT yang sudah dikembangkan adalah model meja. Model ini bentuknya menyerupai meja dengan prinsip pengaliran larutan nutrisi satu bidang".

"Program double track SMA pada awalnya dilakukan untuk mengisi kekosongan terhadap proses industrialisasi di Jawa Timur. Kekosongan tersebut antara lain terlihat dari 
adanya sekitar 90 ribu peluang kerja di Jawa Timur yang tidak bisa diisi karena kompetensi. Sebagai solusi, Pemerintah Provinsi melalui Dinas Pendidikan Provinsi Jawa Timur dengan Dewan Pendidikan mengambil program double track, yang di dalamnya terdapat link and match antara pendidikan dengan lowongan tenaga kerja. Penerapan konsep double track untuk menghadapi pertarungan global dan mengisi tenaga kerja di industri merupakan pengambilan keputusan penting. Double track pada SMA juga sebagai solusi mengatasi permasalahan siswa lulusan SMA yang tidak melanjutkan ke jenjang yang lebih tinggi" (Jurnal Indonesia, 2018).

"Bagi dunia pendidikan, pengangguran masih menjadi masalah. Pemerintah daerah, seperti Dinas Pendidikan (Dispendik) telah melakukan sejumlah inovasi. Sejak 2018, Dispendik Jawa Timur mempunyai program SMA double track, di mana dua kemampuan yang bersifat reguler dan keterampilan yang bersertifikat dibekalkan kepada para siswa SMA. Program ini memberikan ketrampilan tambahan di luar jam pelajaran" (Republika.co.id, 2020).

Program double track merupakan program unggulan SMAN 1 Batur yang bertujuan untuk memberikan keterampilan kepada anak didik di SMAN 1 Batur agar bisa bersaing di masyarakat. Melalui program tersebut siswa di SMAN 1 Batur bisa mendapatkan keahlian ganda, pengetahuan akademik yang didapatkan dari sekolah dan keterampilan beberapa program pilihan yang didapat dari Politeknik Banjarnegara. Keahlian yang dilaksanakan pada tahun 2021 adalah kompetensi pada bidang pengolahan roti, budidaya tanaman hidroponik, dan pemasaran produk.

Salah satu upaya meletakkan dasar jiwa kewirausahaan pada siswa sekolah adalah dengan mengenalkan cara budidaya tanaman yang mudah dan ramah lingkungan. Oleh karena itu perlu untuk dilakukan pengenalan hidroponik. Dengan demikian diharapkan para siswa memiliki pengetahuan, pengalaman, keterampilan dan jiwa kewirausahaan tentang budidaya tanaman secara hidroponik. Lingga (2011) menyatakan bahwa "bertanam secara hidroponik dapat berkembang dengan cepat karena cara ini mempunyai banyak kelebihan. Kelebihan yang utama adalah keberhasilan tanaman untuk tumbuh dan berproduksi lebih terjamin".

Permasalahan yang dihadapi oleh SMAN 1 Batur Banjarnegara adalah tidak tersedianya sarana dan prasarana serta sumberdaya manusia yang mampu untuk memberikan keterampilan dalam ketiga bidang tersebut di atas. Dari hasil diskusi diketahui bahwa sebagian besar para siswa kelas XII yang akan lulus belum mengetahui tentang budidaya tanaman hidroponik, yang merupakan salah satu bidang keahlian program double track SMAN 1 Batur. Oleh karena itu, untuk membekali pengetahuan dan keterampilan para siswa dalam bidang budidaya tanaman hidroponik maka perlu adanya pelatihan pembuatan hidroponik yang sederhana dan mudah dibuat, yaitu hidroponik DFT model meja. Tujuan dari kegiatan pelatihan ini selain memberikan pengetahuan dan keterampilan, juga merupakan salah satu upaya meletakkan dasar jiwa kewirausahaan pada siswa sekolah melalui budidaya tanaman secara hidroponik.

\section{METODE}

\subsection{Waktu dan Tempat}

Pengabdian Kepada Masyarakat (PKM) ini dilaksanakan pada tanggal 7 Desember 2021 di Politeknik Banjarnegara. Metode yang digunakan adalah penyuluhan dan diskusi atau tanya jawab tentang hidroponik dan pelatihan pembuatan hidroponik DFT model meja.

\subsection{Alat dan Bahan}

Alat yang digunakan dalam PKM ini adalah gergaji, pipa pvc, bor listrik, mata bor (hole saw), soldir, kabel roll, spidol permanen, penggaris, rollmeter $5 \mathrm{~m}$, pompa air, ember besar, ember kecil, nampan plastik dan gelas ukur. Sedang bahan yang digunakan adalah pipa pvc $2 \frac{1}{2}$ ",

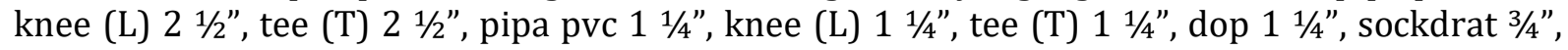
knee (L) $3 / 4$ ", tee (T) $3 / 4 "$, pipa pvc $3 / 4 "$, selang plastik $3 / 4$ " dan 1 ", lem A, solatip, botol plastik, gelas plastik, pupuk AB mix, benih tanaman, rockwool, arang sekam, dan air. 


\subsection{Tahapan Kegiatan}

1. Penyuluhan

Penyuluhan diberikan kepada siswa SMAN 1 Batur guna memberikan dasar-dasar pengetahuan tentang hidroponik, yang meliputi pengetahuan dasar hidroponik, pengenalan media tanam hidroponik, jenis tanaman hidroponik, macam-macam metode hidroponik, nutrisi hidroponik, alat ukur hidroponik, serta, gangguan hama dan penyakit.

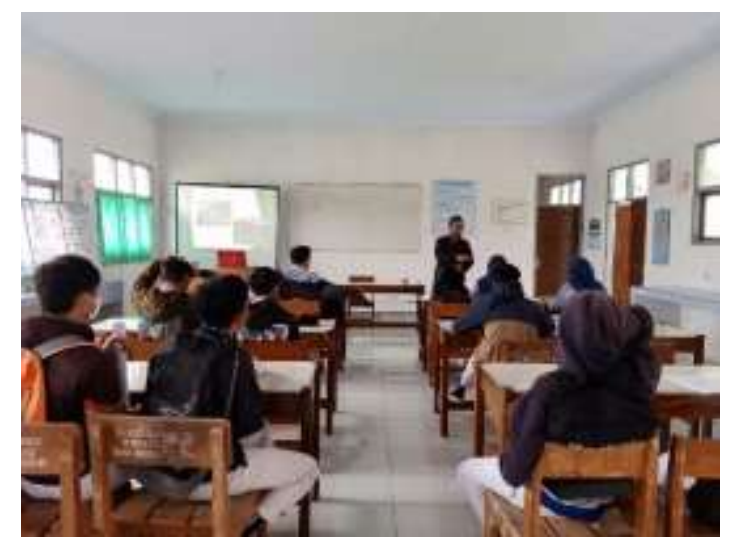

Gambar 1. Penyuluhan dan diskusi tentang hidroponik

\section{Pelatihan}

Pelatihan diberikan kepada siswa SMAN 1 Batur dengan tujuan untuk memberikan keterampilan tentang budidaya tanaman secara hidroponik, yaitu praktik menyemai benih hidroponik, praktik pembuatan larutan nutrisi hidroponik, dan praktik pembuatan hidroponik DFT model meja.

a. Praktik persemaian benih hidroponik dilakukan dengan menggunakan media semai rockwool dengan ukuran $2,5 \mathrm{~cm}$ x 2,5 $\mathrm{cm}$ x 2,5 cm. Benih yang disemaikan adalah benih pakcoy, dengan jumlah satu benih untuk setiap media semai rockwool.

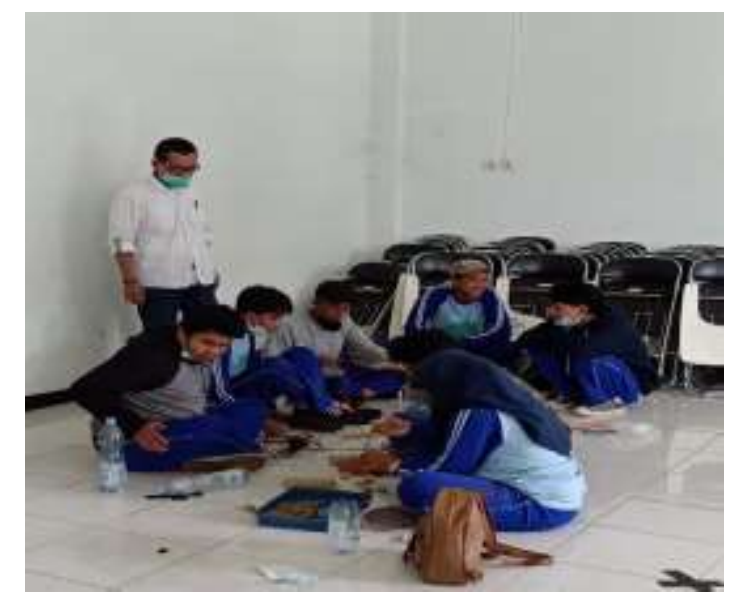

Gambar 2. Praktik persemaian benih hidroponik

b. Praktik pembuatan larutan nutrisi dilakukan dengan menggunakan pupuk AB mix. Praktik dimulai dengan pembuatan pekatan A dan pekatan B yang masing-masing sebanyak $500 \mathrm{ml}$, serta dimasukkan dalam botol plastik secara terpisah. Selanjutnya pekatan A+B dicampur dengan air dengan perbandingan 1:100. Larutan nutrisi siap digunakan untuk budidaya tanaman secara hidroponik. 


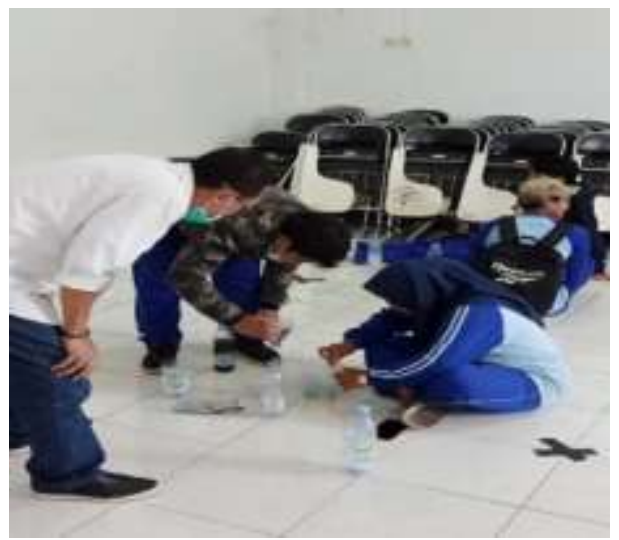

Gambar 3. Praktik pembuatan larutan nutrisi

c. Praktik pemotongan pipa pvc dilakukan pada pipa ukuran 2 1/2", 1 1/4" dan 3/4" sesuai dengan ukuran panjang yang telah ditentukan.

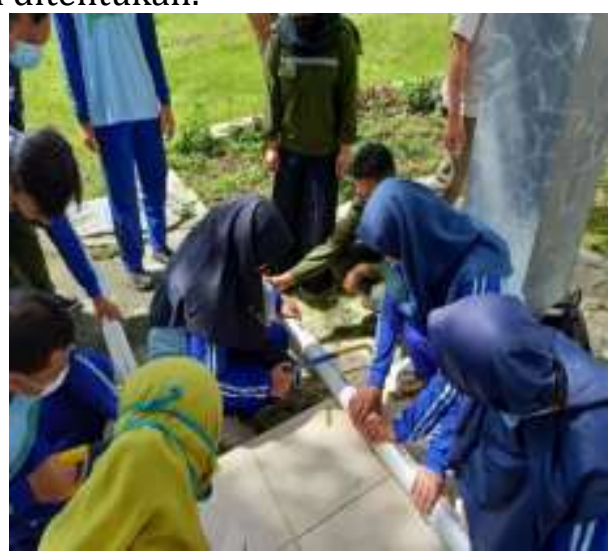

Gambar 4. Praktik pemotongan pipa pvc

d. Praktik pengeboran pipa pvc dilakukan dengan menggunakan bor listrik dengan mata bor hole shaw. Jarak antar titik bor satu dengan titik lainnya adalah $11 \mathrm{~cm}$. Sebelum dibor, titik yang sudah ditandai dengan spidol disoldir agar pada saat pengeboran tidak meleset.

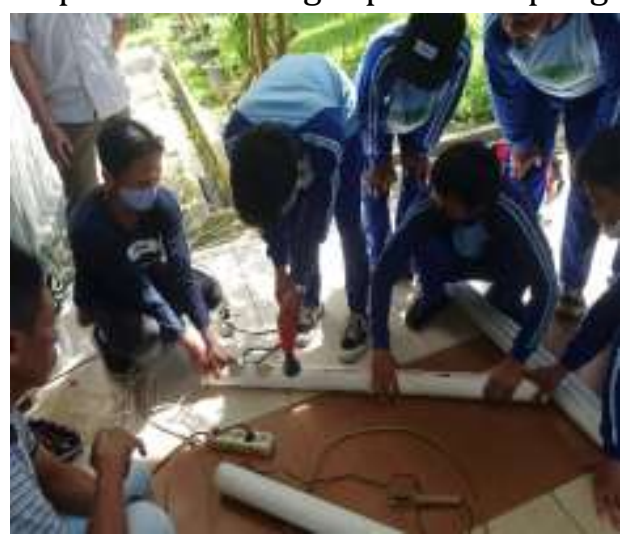

Gambar 5. Praktik pengeboran pipa pvc

e. Praktik merangkai konstruksi hidroponik DFT model meja dilakukan setelah selesai praktik pemotongan dan pengeboran pipa pvc. Rangkaian konstruksi hidroponik DFT model meja dibuat sesuai dengan gambar konstruksi yang telah diberikan. 


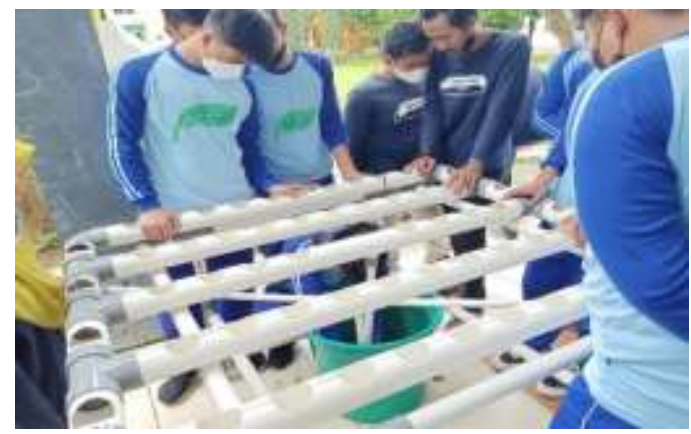

Gambar 6. Praktik merangkai konstruksi hidroponik DFT model meja

f. Praktik pemindahan tanaman dilakukan setelah rangkaian konstruksi hidroponik DFT model meja selesai dibuat. Bibit tanaman pakcoy yang sudah tumbuh 3-4 helai daun dimasukkan dalam gelas plastik yang berisi arang sekam, dan selanjutnya dimasukkan ke dalam lubang yang terdapat pada konstruksi hidroponik DFT model meja.

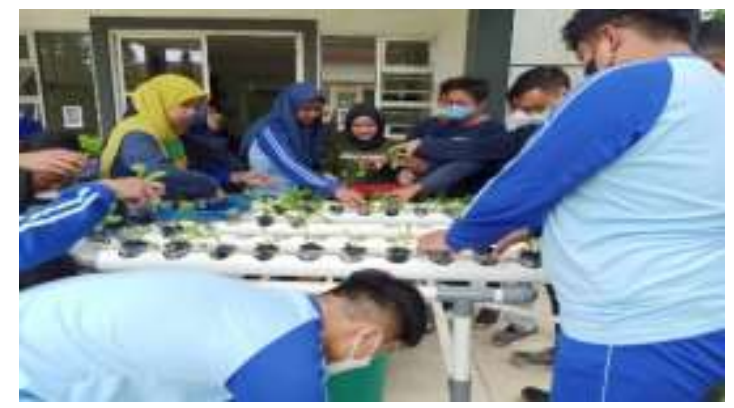

Gambar 7. Praktik pemindahan tanaman

g. Hasil pelatihan pembuatan hidroponik DFT model meja kepada siswa SMAN 1 Batur.

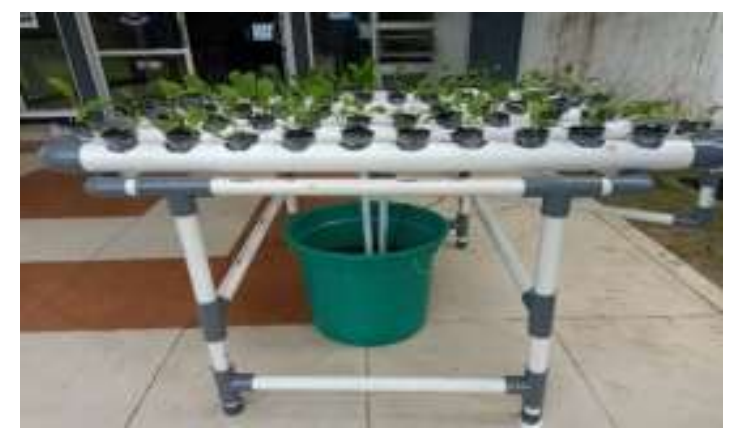

Gambar 8. Hasil pembuatan hidroponik DFT model meja

\section{HASIL DAN PEMBAHASAN}

\subsection{Penyuluhan}

Para siswa SMAN 1 Batur mengikuti penyuluhan dengan antusias. Hal ini ditunjukkan dengan beberapa pertanyaan yang diajukan oleh para siswa pada saat kegiatan penyuluhan. Dari diskusi dan tanya jawab menunjukkan hampir seluruh peserta belum mengetahui tentang budidaya tanaman secara hidroponik.

Tingkat pengetahuan para siswa tentang hidroponik DFT, pupuk AB mix, dan rockwool masih rendah. Menurut (Wibowo, 2021a) "hidroponik Deep Flow Technique (DFT) adalah suatu 
metode hidroponik di mana akar tanaman berada dalam genangan larutan nutrisi dengan ketinggian 3-4 cm". Selanjutnya Agustina (sebagaimana dikutip dalam Sesanti \& Sismanto, 2016) menyatakan bahwa "dalam budidaya hidroponik, pupuk yang digunakan adalah pupuk AB mix yang mengandung 16 unsur hara yang dibutuhkan oleh tanaman. Unsur hara tersebut dibagi menjadi unsur hara makro (dibutuhkan dalam jumlah banyak, yaitu N, P, K, Ca, Mg, S) dan unsur hara mikro (dibutuhkan dalam jumlah sedikit, yaitu $\mathrm{Na}, \mathrm{Bo}, \mathrm{Fe}, \mathrm{Zn}, \mathrm{Mn}, \mathrm{Si}, \mathrm{Cl}, \mathrm{Cu}, \mathrm{Co}, \mathrm{Mo}$ )". Pada saat ini media tanam yang populer digunakan dalam budidaya tanaman seara hidroponik adalah rockwool. Menurut Marlina et. al. (sebagaimana dikutip dalam Ningsih et al., 2020) bahwa "media tanam rockwool mempunyai beberapa kelebihan, diantaranya berperan dalam sebagai ganti pupuk, dapat digunakan berkali-kali, bebas penyakit tanaman, menghemat disinfektan, serta berpengaruh terhadap pertumbuhan dan produksi tanaman".

\subsection{Pelatihan}

Para siswa SMAN 1 Batur juga mengikuti pelatihan dengan penuh semangat. Hal ini disebabkan karena seluruh peserta belum memiliki keterampilan dan pengalaman dalam budidaya tanaman secara hidroponik, yang meliputi praktik persemaian tanaman sampai dengan pembuatan metode/konstruksi hidroponik. Pelatihan pembuatan hidroponik DFT model meja diberikan agar para siswa memiliki keterampilan dalam pembuatan konstruksi metode hidroponik yang menggunakan pipa pvc, yang meliputi bahan-bahan yang digunakan, cara pemotongan dan pembuatan lubang pipa, serta cara merangkai pipa menjadi konstruksi hidroponik DFT model meja.

Tingkat pengetahuan para siswa tentang alat yang digunakan dalam pembuatan lubang pipa pvc masih rendah. Demikian pula, tingkat keterampilan para siswa dalam persemaian, pembuatan larutan nutrisi, dan merangkai hidroponik DFT model meja masih rendah. Persemaian dilakukan dalam nampan plastik dengan menggunakan media semai rockwool. Menurut Wibowo (2021) bahwa "persemaian dilakukan selama \pm 2 minggu atau daun tanaman tumbuh 3-4 helai".

Larutan nutrisi yang digunakan dalam budidaya hidroponik menggunakan pupuk $A B$ mix. Pembuatan larutan nutrisi ini harus memenuhi aturan yang sudah ditetapkan agar konsentrasinya sesuai dengan kebutuhan tanaman. Berdasarkan hasil penelitian yang dilakukan oleh Wibowo (2021b) diketahui bahwa "konsentrasi nutrisi 1.000 ppm, dengan perbandingan antara pekatan $A+B$ dengan air adalah 1:100, berpengaruh lebih baik terhadap produksi tanaman". Oleh karena itu, dalam praktik para siswa diajarkan pembuatan pekatan A dan pekatan B dengan volume masing-masing $500 \mathrm{ml}$. Selanjutnya untuk $50 \mathrm{ml}$ pekatan A dan $50 \mathrm{ml}$ pekatan B (total $100 \mathrm{ml}$ pekatan A+B) dicampur dengan $10.000 \mathrm{ml}$ (10 liter) air, dan larutan nutrisi siap digunakan untuk budidaya tanaman hidroponik.

Alat yang digunakan dalam pembuatan lubang pipa adalah bor listrik yang ditambah mata bor hole saw sesuai dengan ukuran lubang yang akan dibuat (umumnya ukuran 2 inci). Sebelum dibor, titik pada pipa disoldir sebagai pegangan besi mata bor agar pada saat pengeboran tidak meleset. Selanjutnya pipa yang sudah dilubangi dengan bor listrik dan dipotong-potong panjangnya sesuai ukuran yang telah ditentukan, dirangkai konstruksinya menjadi hidroponik DFT model meja. Untuk menghindari adanya kebocoran larutan nutrisi maka pada sambungan pipa diberi solatip atau lem A.

\subsection{Pengukuran tingkat pengetahuan dan keterampilan}

Untuk mengetahui capaian kegiatan yang dilakukan maka pada awal dan akhir kegiatan diberikan kuesioner kepada para siswa yang berisikan materi kegiatan penyuluhan dan pelatihan tentang hidroponik, dan hasilnya disajikan pada Tabel 1. 
Tabel 1. Hasil pengukuran tingkat pengetahuan dan keterampilan siswa SMAN 1 Batur tentang hidroponik

\begin{tabular}{|c|c|c|}
\hline No. & Awal kegiatan & Akhir kegiatan \\
\hline 1 & $\begin{array}{l}\text { Tingkat pengetahuan tentang } \\
\text { hidroponik DFT model meja masih } \\
\text { rendah (semua peserta tidak tahu = } \\
0 \% \text { ) }\end{array}$ & $\begin{array}{l}\text { Tingkat pengetahuan tentang } \\
\text { hidroponik DFT model meja } \\
\text { meningkat }(15 / 17 \text { peserta }=88 \% \\
\text { peserta tahu) }\end{array}$ \\
\hline 2 & $\begin{array}{l}\text { Tingkat pengetahuan tentang pupuk } \\
\text { AB mix masih rendah (semua } \\
\text { peserta tidak tahu }=0 \% \text { ) }\end{array}$ & $\begin{array}{l}\text { Tingkat pengetahuan tentang pupuk } \\
\text { AB mix meningkat }(16 / 17 \text { peserta }= \\
94 \% \text { peserta tahu) }\end{array}$ \\
\hline 3 & $\begin{array}{l}\text { Tingkat pengetahuan tentang media } \\
\text { semai rockwool masih rendah } \\
\text { (semua peserta tidak tahu }=0 \% \text { ) }\end{array}$ & $\begin{array}{l}\text { Tingkat pengetahuan tentang media } \\
\text { semai rockwool meningkat (semua } \\
\text { peserta tahu }=100 \% \text { ) }\end{array}$ \\
\hline 4 & $\begin{array}{l}\text { Tingkat pengetahuan tentang alat } \\
\text { yang digunakan dalam pembuatan } \\
\text { lubang pipa pvc masih rendah } \\
\text { (semua peserta tidak tahu }=0 \% \text { ) }\end{array}$ & $\begin{array}{l}\text { Tingkat pengetahuan tentang alat } \\
\text { yang digunakan dalam pembuatan } \\
\text { lubang pipa pvc meningkat }(16 / 17 \\
\text { peserta }=94 \% \text { peserta tahu) }\end{array}$ \\
\hline 5 & $\begin{array}{l}\text { Tingkat keterampilan dalam } \\
\text { persemaian tanaman hidroponik } \\
\text { masih rendah (semua peserta tidak } \\
\text { bisa }=0 \% \text { ) }\end{array}$ & $\begin{array}{l}\text { Tingkat keterampilan dalam } \\
\text { melakukan persemaian tanaman } \\
\text { hidroponik meningkat (semua peserta } \\
\text { bisa }=100 \% \text { ) }\end{array}$ \\
\hline 6 & $\begin{array}{l}\text { Tingkat keterampilan dalam } \\
\text { pembuatan larutan nutrisi } \mathrm{AB} \text { mix } \\
\text { masih rendah (semua peserta tidak } \\
\text { bisa }=0 \% \text { ) }\end{array}$ & $\begin{array}{l}\text { Tingkat keterampilan dalam } \\
\text { pembuatan larutan nutrisi } \mathrm{AB} \text { mix } \\
\text { meningkat (semua peserta bisa = } \\
100 \% \text { ) }\end{array}$ \\
\hline 7 & $\begin{array}{l}\text { Tingkat keterampilan dalam } \\
\text { pengeboran lubang pada pipa pvc } \\
\text { masih rendah (semua peserta tidak } \\
\text { bisa }=0 \% \text { ) }\end{array}$ & $\begin{array}{l}\text { Tingkat keterampilan dalam } \\
\text { pengeboran lubang pada pipa pvc } \\
\text { meningkat }(15 / 17 \text { peserta }=88 \% \\
\text { peserta bisa) }\end{array}$ \\
\hline 8 & $\begin{array}{l}\text { Tingkat keterampilan dalam } \\
\text { merangkai hidroponik DFT model } \\
\text { meja masih rendah (semua peserta } \\
\text { tidak bisa }=0 \% \text { ) }\end{array}$ & $\begin{array}{l}\text { Tingkat keterampilan dalam } \\
\text { merangkai hidroponik DFT model } \\
\text { meja meningkat ( } 14 / 17 \text { peserta = } \\
82 \% \text { peserta bisa) }\end{array}$ \\
\hline
\end{tabular}

Pengukuran tingkat pengetahuan dan keterampilan siswa SMAN 1 Batur tentang hidroponik dilakukan terhadap 17 siswa, dengan jenis kelamin 13 laki-laki dan empat perempuan. Hasil pengukuran pada Tabel 1 menunjukkan bahwa pada awal kegiatan tingat pengetahuan dan keterampilan para siswa masih rendah, semua peserta belum memiliki pengetahuan dan keterampilan tentang hidroponik. Pada akhir kegiatan tingkat pengetahuan siswa meningkat 88\%-100\% dengan rata-rata 94\%, sedang tingkat keterampilan siswa meningkat $82 \%-100 \%$ dengan rata-rata 92,5\%. Hal ini menunjukkan bahwa para siswa mengikuti penyuluhan dan pelatihan hidroponik dengan antusias dan penuh semangat, sehingga mampu menyerap materi penyuluhan dan pelatihan tentang hidroponik yang diberikan. 


\section{KESIMPULAN}

Berdasarkan kegiatan pengabdian kepada masyarakat ini dapat disimpulkan bahwa siswa SMAN 1 Batur mengikuti penyuluhan dan pelatihan hidroponik dengan antusias dan penuh semangat, sehingga mampu menyerap materi penyuluhan dan pelatihan yang diberikan. Tingkat pengetahuan para siswa tentang hidroponik meningkat $88 \%-100 \%$ dengan rata-rata $94 \%$, sedang tingkat keterampilan siswa dalam pembuatan konstruksi hidroponik meningkat 82\%-100\% dengan rata-rata $92,5 \%$.

\section{UCAPAN TERIMA KASIH}

Penulis mengucapkan terima kasih kepada pihak sekolah yang mendukung kegiatan ini melalui program double track SMA Negeri 1 Batur Banjarnegara sehingga dapat terlaksana dengan baik dan lancar.

\section{DAFTAR PUSTAKA}

Gayatri, L. P. Y. R., \& Mahyuni, L. P. (2021). Pengenalan Sistem Pertanian Hidroponik Rumah Tangga di Desa Dalung. Dinamisia: Jurnal Pengabdian Kepada Masyarakat, 5(6), 14031412. https://doi.org/10.31849/dinamisia.v5i6.6303

Ginting, C. (2019). Teknik Budidaya Tanpa Tanah Tanaman Hortikultura: Solusi untuk Pertanian Kota. Instiper Press.

Hidayah, A. L., Dwiratna, S., Prawiranegara, B. M. P., \& Amaru, K. (2020). Kinerja dan Karakteristik Konsumsi Energi, Air, dan Nutrisi pada Sawi Pagoda (Brassica narinosa) Menggunakan Sistem Fertigasi Deep Flow Technique (DFT). Jurnal Keteknikan Pertanian Tropis Dan Biosistem, 8(2), 125-134. https://doi.org/10.21776/ub.jkptb.2020.008.02.02

Jurnal Indonesia. (2018). Pentingnya Pendidikan Double Track SMA. Jurnal Indonesia. https://doi.org/https://www.jurnalindonesia.net/pentingnya-pendidikan-double-tracksma/

Lingga, P. (2011). Hidroponik, bercocok tanam tanpa tanah (XXXII). Penebar Swadaya.

Ningsih, E., Agus Budianto, Kartika Udyani, Yustia Wulandari M, Shofiyya Julaika, \& Dian Yanuarita P. (2020). Pemberdayaan Pemberdayaan Karang Taruna Desa Gampingrowo dengan Pelatihan Hidroponik. Dinamisia: Jurnal Pengabdian Kepada Masyarakat, 4(2), 333-338. https://doi.org/10.31849/dinamisia.v4i2.4033

Republika.co.id. (2020). 2 Kompetensi SMA Double Track Dorong Kemandirian Siswa. Republika.Co.Id. https://doi.org/https://republika.co.id/berita/pendidikan/eduaction/qiz09t320/2kompetensi-smaem-double-trackem-dorong-kemandirian-siswa

Sesanti, R. N., \& Sismanto. (2016). Pertumbuhan dan Hasil Pakchoi (Brasicca rapa L.) pada Dua Sistem Hidroponik dan Empat Jenis Nutrisi. Jurnal Kelitbangan, 04(01), 1-9.

Wibowo, S. (2020). Pengaruh Aplikasi Tiga Model Hidroponik DFT Terhadap Tanaman Pakcoy (Brassica rapa L.). Jurnal Keteknikan Pertanian Tropis Dan Biosistem, 8(3), 245-252. https://doi.org/10.21776/ub.jkptb.2020.008.03.06

Wibowo, S. (2021a). Pemanfaatan Kolam Ikan Untuk Budidaya Tanaman Dengan Aquaponik. Dinamisia: Jurnal Pengabdian Kepada Masyarakat, 5(4), 921-927. https://doi.org/10.31849/dinamisia.v5i4.7161

Wibowo, S. (2021b). Pengaruh Jenis Sumbu Dan Konsentrasi Nutrisi Terhadap Sawi Samhong (Brassica juncea L.) Dengan Hidroponik Sistem Sumbu. Jurnal Paspalum, 9(2), 181-191. 